\title{
FAMÍLIA: COMUNIDADE DE VIDA E DE AMOR
}

FAMILY: COMMUNITY OF LIFE AND LOVE

Frei Almir Ribeiro Guimarães, OFM ${ }^{1}$

GUIMARÃES , A. R. Familia: Comunidade de Vida e de Amor. Rev. Bras. Cres. Des. Hum., São Pauio, IV(1), 1994.

Resumo: Através do texto o autor defende a idéia de que a fam 1ia deva ser uma comunidade de pessoas, pois, no mundo de hoje, onde predomina a competição, a discriminação e o individualismo; a fam1ia aparece como lugar de acolhimento afetivo, de expressão de carinho, de aceitação de seus membros e espaço natural de desenvolvimento do ser humano. A partir deste enfoque, o autor faz considerações sobre alguns temas importantes: casamento, amor, sexualidade, filhos e justiça social, como sendo fundamentais para a construção da fam ia, mola propulsora de uma sociedade humana, solidária, justa e altruísta.

Palavras-Chave: Fam1ia, comunidade de vida, casamento, amor.

Summary: Through the text the author supports the idea that the family must be a community of people, because in today's world where competition, discrimination and individualism predominate, the family appears as a place of caring and sharing, where its members are accepted and where they can express their feelings of affection; a natural space of the development of the human being.

From this point of view the author focuses on some important themes: marriage, love, sexuality, children and social justice, considering them to be fundamental to the construction of the family, the propellant string of a human, solidary, just and altruistic society.

Key-words: Family, life community, marriage, love.

1 Frade Franciscano pertencente à Ordem dos Frades Menores e asscssor do Setor Família da Conferência Nacional dos Bispos do BradL Setor Famíia

End.: SE/Sul Quadra 801 Conjunto “B” - Brasília - DF CEP 70259-970 Fone: (061) 225.2955 Fax: (061) 225.4361. 


\section{INTRODUÇÃO}

O Ano Internacional da FamDia, decretado pela ONU, foi certamente ocasião de muita reflexão sobre esta pequena célula tão “amada” e ao mesmo tempo tão contestada Muitos tiveram na vida experiências tão traumatizantes que preferem não refletir sobre o sentido dessa união de um homem e de uma mulher e que está aberta a acolhida de filhos, rasgando sua história no tempo que passa Nosso propósito não é dissertar longa e exaustivamente sobre o tema. Desejamos apenas ver na famDia, apesar de todas as dificuldades, uma comunidade de vida e de amor.

Conhecemos algumas transformações muito importantes na história da familiar Ternpos houve em que ela parecia mais uma unidade económica em que as tarefas eram distribuídas de maneira a que os bens patrimoniais se perpetuassem, aumentassem ou não viessem a faltar. Não poucas vezes casamento e famDia eram realidades frias, onde havia pouco espaço para o afeto, o carinho e a ternura. A mulher sempre pareceu ter sido esquecida. Não poucas vezes era profundamente desrespeitada, vivendo em estado de "minoridade". O autoritarismo, o machismo e o legalismo dominavam de tal forma que pareciam instransponíveis.

Só bem recentemente a família foi conhecer o espaço para o amor interpessoal, para a demonstração de carinho, para a construção de uma história conjugal e familiar. Estamos ainda tentando ver mais claro o que seria uma família para nossos tempos.

\section{FAMÍLIA: COMUNIDADE DE PESSOAS}

Não basta dizer que família seja o conjunto de pessoas aparentadas, que em geral, vivem na mesma casa, pessoas do mesmo sangue. Devemos dizer que toda famDia é uma comunidade. A palavra comunidade se opõe ao individual, ao que é de uns e não de outros. Na realidade quando um homem e uma mulher se encontram, desejam com toda força criar um novo, uma comunidade onde serão colocadas juntas as riquezas, potencialidades, possibilidades de um e de outro. No momento do casamento há um deixar alguma coisa para trás e a vontade empenhada de criar comunidade de vida. Não se trata apenas de comunidade de bens, mas de pessoas. A vida e a história de duas pessoas se entrecruzam. Insistimos na dimensão do encontro de pessoas. A pessoa é única. Não pode ser diminuída, reduzida a coisa, colocada em posição de inferioridade. Nunca pode ser aviltada, espezinhada, aniquilada. A pessoa é inteligência, vontade, desejo, ânsia, coração, afeto. Há o tempo do namoro. Há o tempo do conhecimento. Aos poucos duas histórias que vão fazendo o dom de pessoa a pessoa, a partir do coração, isto devido à uma admiração. Juntando essas histórias se transformarão numa outra história Colocam em comum suas histórias pessoais e começam a construção da conjugalidade. Quando alguém se casa com alguém há uma revolução interior importantíssima. O poeta já dizia que somos eternamente responsáveis por aquilo que cativamos. Importante insistir: trata-se de uma comunidade de pessoas que respeita a diferença e a alteridade. Não há papéis previamente armados e pré-fixados. Há uma história de comunidade que vai se transformando em comunhão. $\mathrm{O}$ tempo do namoro é o tempo do desejo.

\section{TENDO COMO BASE O DOM DE PESSOAA PESSOA}

O amorinterpessoal é fundamental na compreensão da realidade do casamento e da familiar É a liberdade de cada um que escolhe uma outra liberdade para fazer a mais importante experiência da vida: o amor. Não basta apenas haver uma atração física por mais importante que esta seja para o sucesso da vida conjugal e familiar. Será necessário um querer bem mais profundo. Tratase de um desejo firme de tornar a(s) outra(s) pessoa(s) (o cônjuge e os filhos) profundamente felizes e ajudá-los a colocarem em ato todas as suas possibilidades. Esse amor significará acolhimento, desejo de escuta, respeito terno pela maneira de ser diferente do outro, compromisso. Sé ama quem é capaz de comprometer-se com um alguém. Lamentavelmente, muitos jovens nunca fizeram uma experiência pessoal de dom. Sempre foram poupados na vida e aprenderam que eles são o "centro" do mundo. Nossa cultura é a da subjetividade exacerbada e de um individualismo que não respeita a existência de outras pessoas com suas riquezas. O amor conjugal é totalizaste e totalizador. Comporta entrega total e definitiva. O amor é exigente, não se satisfaz com aspectos laterais da pessoa. Ama-se no presente, na serena convicção de que se continuará amando no tempo que vai se desdobrando.

Necessário se faz rever a educação para o amor. Esta precisará dispor as pessoas para a possibilidade de entrega de pessoa a pessoa. $\mathrm{O}$ amor comporta responsabilidade. Marido e mulher, pais e filhos, na dinamica do amor gratuito, livre, desinteressado, respeitoso, são responsáveis uns pelos outros.

Em nossos dias há a prática da sexualidade na adolescência, desvinculada do amor verdadeiro, separada de um compromisso. Não existe verdadeiro amor, há somente uma satisfação epidérmica sexual, embora o encontro doscorpos precise ser a celebração de uma entrega que vai além da genitalidade. Toda a concepção 
atual da sexualidade deveria conhecer seria reorientação, Sem isto, o casamento e a família estarão comprometidos definitivamente.

É precisamente um amor maduro e responsável que gera vida na vida do casal. Quantos jovens casados já não experimentam mais viço e vigor em sua união porque lhes falta a base de um amor verdadeiro?

\section{NUMA RELAÇÃO ESTÁVEL E DURADOURA}

Para nossos contemporâneos, casamento e família são realidades que não precisam durar, sobretudo não podem ou não devem durar para sempre. Certamente há casamentos que não podem ser sustentados: há casos de infidelidade crassas, de alcoolismo, de violência. Normalmente, no entanto, não se deveria defender, sem mais, o divórcio. 0 casal não se cria de imediato. Ele precisa do tempo da convivência, dos anos de amadurecimento, da sucessão de gostos de entrega, da coragem do perdão quando este se fizer oportuno e necessário. O momento das núpcias e os primeiros tempos de convivência são insuficientes para a construção do nos do casal. Parece de fundamental importância que os jovens casais aprofundem os laços que os unem, vençam normais dificuldades e superem conflitos eventuais. Fundamental é a preparação para a acolhida dos filhos nos primeiros anos de vida conjugal.

Na realidade a decisão do casamento que parte do fundo do coração e que atinge o nó da pessoa não pode deixar de ser estável e duradoura.

Desnecessário dizer que os filhos são os que mais sofrem com a instabilidade do vínculo conjugal. É verdade que, em algumas situações, o clima no lar é tal que o único caminho parece ser a separação. Mas para que isto aconteça, torna-se necessário esgotar todos os recursos e buscar todos os expedientes para superar a crise. Meninos e meninas, adolescentes e jovens experimentam profundo desequilíbrio interior com a separação dos pais e com ingresso, no universo familiar, de um "outro pai” ou "outra mãe". Nas classes menos favorecidas, nos segmentos médios e nas classes altas, a instabilidade do vinculo e seu rompimento são causas de problemas quase que insolúveis. Tudo isso porque família e casamento são realidades que precisam prolongar-se no espaço e no tempo e revestir-se de durabilidade.

Na realidade o projeto sonhado pelo homem e pela mulher precisa destas características: certeza de duração e estabilidade do relacionamento. Desnecessário dizer que vivemos uma época de fragilidade do vínculo conjugal. Vivendo a época do descartável e do provisório, homem e mulher, mais ou menos insensivelmente, foram aceitando o rompimento de sua união e constituindo novas uniões. Mesmo sem se fazer apelo à doutrina da indissolubilidade conjugal defendida pela Igreja Católica, precisamos afirmar que a desestabilização conjugal é nociva para o surgimento de uma família sadia Cônjuges e filhos saem perdendo.

\section{EM VISTA DA REALIZAÇÃO DAS PESSOAS}

Homem e mulher não se encontram por fatalidade. Um é feito para o outro. Há uma complementação entre masculino e feminino. A humanidade completa é mascu]ina e feminina. Por isso o casamento tem como finalidade a realização do masculino e do feminino numa comunidade de vida. Os textos bíblicos falam da criação do homem. Adão recebe todo o universo. Percorre tudo o que é criado. Não encontra um igual. $\mathrm{O}$ livro do Gênesis assim se exprime depois de descrever a cria,cão da mulher: "Eis agora aqui, disse o homem, o osso de meus ossos e a carne de minha carne; ela se chamará mulher, porque foi tomada do homem". Esta é a expressão do homem ao ver a mulher. E o autor do texto sagrado continua: "Por isso o homem deixará o pai e a mãe, se unirá à sua mulher e se tornarão uma sé carne" (GÊNESIS, 2, 18-25).

Esta busca do homem pela mulher e da mulher pelo homem se inscreve na própria natureza de seu ser. Homem e mulher formam uma única realidade porque não podem ser eles mesmos sozinhos. Não é bom que o homem viva só. A mulher Ihe é dada como companheira de destino, como ajuda na realização de seu ser e viceversa

As pessoas se casam porque sentem necessidade de exprimir seu amor, colocar com um outro diferente/igual suas potencialidades, dar e receber. A união do feminino e do masculino chega até o encontro íntimo dos corpos que é a celebração dessa entrega irrestrita. Uma das finulidades do casamento é precisamente essa complementação entre masculino e feminino, porque os dois juntos é que constituem o ser humano completo.

\section{ABERTURA À ACOLHIDA DOS FILHOS}

Podemos dizer que os filhos são fruto natural do amor conjugal. Normalmente falando, um casal que se entrega percebe que seu amor poderá ganhar materialização importante quando da chegada dos Slhos. Nossos tempos compreenderam que os filhos precisam ser espaçados. Devido a múltiplos fatores, os pais procuram programar a chegada dos filhos. Fala-se hoje, mais do 
que nunca, num planejamento familiar e numa paternidade e maternidade responsável. Perfeitamente normal que assim se proceda.

Somos obrigados, porém, a reconhecer que há, em nossos tempos, uma mentalidade antivida Fala-se de ecologia, respeito pela vida dos rios, dos mares, das plantas, do ar, mas com certa facilidade se rejeita a chegada do filho e chega-se mesmo a aceitar como normal e natural o aborto. Fala-se também em cultura de morte. O Documento da IV Conferência dos Bispos da América Latina, em Santo Domingo, assim se exprime: "A cultura de morte nos desafia. Com tristeza humana e preocupação cristã, somos testemunhas das campanhas antivida, que se difundem na América Latina e no Caribe, perturbando a mentalidade de nosso povo com uma cultura de morte. O egoísmo, o medo ao sacrifício e à cruz unidos às dificuldades da vida moderna geram uma rejeição do filho que não é responsável e alegremente acolhido na família, mas considerado como um agressor”.

Um casal que inaugura a vida a dois e familiar coloca como um projeto importante de seu bem querer a acolhida dos filhos. Somente é possível que tal plano se concretize quando o casal tem segurança da estabilidade de sua união. Somente dentro de uma família bem constituída é que se pode pensar na acolhida dos filhos. Todas as relações pré-matrimoniais e fora do casamento são espaços de instabilidade e portanto inadequados para a acolhida de uma criança. A criança é um ser frágil e se não encontra, à sua chegada, ambiente de segurança e amor conhecerá problemas sérios em seu desenvolvimento. A criança precisa de pão, veste, escola, instrução, mas necessita, antes de tudo, ser acolhida como pessoa, como dádiva, como presente da vida. Precisando de carinho e proteção, a criança que chega solidifica a união conjugal. A comunidade de vida e de amor, que é a família, vê-se enriquecida com a chegada e acolhimento dos filhos.

Insistimos: necessário vencer uma mentalidade antivida. Damos novamente a palavra ao Documento de Santo Domingo: "Existe uma distribuição massiva de anticoncepcionais, em sua grande maioria abortivos. Imensos selares de mulheres são vítimas de programas de esterilizações massivas. Também os homens sucumbem ante estas ameaças”.

Num contexto de miséria material e social, colocase o problema das formações familiares nas classes menos favorecidas. Se o problema da acolhida dos filhos se dá nas classes remediadas, mais grave ele é entre os mais pobres da terra. Muitos rapazes e moças, sem formação humana, vivendo em condições indignas, mal alimentados e subempregados, começam uma vida a dois. Não a selam com o casamento civil, nem com o sacra- mento do matrimonio. Vivem uns tempos juntos. Colocam filhos e filhas no mundo. Desfazem a união. Unem-se com outras pessoas. Geram novos filhos e filhas. Estas crianças, nascidas em tais condições, não conseguem realizar-se. Muitos deles e delas tornam-se meninos e meninas de rua Cabe ao Estado dar condições para que as famílias sejam constituídas dignamente. Uma justiça social faz-se necessária para o bem da humanidade.

João Paulo II, dirigindo carta aos Chefes de Estado, a respeito da Conferência do Cairo sobre População e Desenvolvimento, assim se exprime: “... uma instituição natural tão fundamental e universal (como a família) não pode ser manipulada por ninguém. Quem poderia dar um tal mandato a indivíduos e instituições? A família pertence ao património da humanidade! (Carta aos Chefes de Estado, 19 de março de 1994). O Papa, aludindo ã questão abortista, lembra que a família é património da humanidesde.

Muitos casais não estão preparados para a paternidade. Torna-se necessário que os jovens esposos possam se preparar para tanto.

\section{ESPAÇO DE EDUCAÇÃO DOS FILHOS}

Missão importante da família é a educação dos filhos. Não se trata apenas de colocar crianças no mundo. Esses filhos são acolhidos no espaço familiar para que ali encontrem sentido para suas vidas e venham a ser cidadãos. Através da conduta dos pais, pelos procedimentos que vão tomando, os filhos tomam conhecimento da realidade e são educados. Complexo é o processo de educação de um ser humano. Todos precisam ser colocados diante de valores que estruturem sua personalidade. Ninguém pode ser educado sem um horizonte de valores e pontos de referência. Uma criança que crescesse na rua, que nunca fosse alertada a respeito do relacionamento entre as pessoas, do respeito pelo direito dos outros, pelo valor e dignidade da liberdade, pela paixão que se deve ter pela lisura e honestidade seria um ser sem estrutura interior, sem critérios valorativos e um imprestável para a sociedade. Por isso se diz, com toda razão, que é na família que se forja o caráter, aprende-se a solidariedade, exercita-se a convivência e criam-se convicções.

O ser humano é um mistério. Cada criança, adolescente e jovem cresce envolto nesse mistério do existir humano. Parece fundamental que o homem seja alertado, também, para suadimensão transcendente. Viver não é somente girar no universo da matéria. O ser humano é ser relações. É feito para a comunhão. É ser social. Mais ainda: há dentro do homem de "coração feto" um desejo de busca do Absoluto. Nosso coração sé descansa em Deus. Ora, é precisamente uma família sólida e estável 
que pode despertar em seus membros o desejo de busca, de encontro e de comunhão com o Altíssimo e Deus Magnifico. A família, comunidade de pessoas e de amor, é o único espaço natural para a descoberta de Deus. Cabe aos pais, sem imposição, descortinar aos olhos dos filhos esse desejo de conhecer o Mistério do Senhor.

\section{FAMÍLIA PARA NOSSOS TEMPOS}

\section{Constante criação}

A família muda e evolui, como mudam e evoluem as pessoas que a constituem. No começo está o jovem casal com seus planos e alguns projetos já delineados. No final está um casal de anciães, cheio de recordações e lembranças. Entre um e outro extremo, uma pequena comunidade, com ele e ela, os meninos e as meninas. Uma vez crescidos, estes partem pelo mundo. A família vai mudando ao longo do tempo. Há um filho que chega com saúde e outro doente. Há um luto aqui e uma novidade ali. A família está sempre em construção. Vai se adaptando às novas circunstâncias. Importante que tenha como base o amor e o desejo de que a comunidade perdure pelo tempo, apesar de todas as dificuldades. Tudo existe em função desse amor. Sem ele não há família que possa “ficar de pé”. Falar de família é falar de uma corrente de amor capaz de superar conflitos, dificuldades e tensões.

O amor faz projetos. Há o projeto do rapaz. Há a vida do rapaz e sua história familiar. Há o projeto e a vida da moça e sua trajetória familiar. Os dois se encontram e criam o novo, a nova família. Necessário tirar as familias do marasmo. Cada família tem que realizar sua construção. Apoiando-se em princípios sólidos, a família tem que ter a capacidade de criar o novo.

\section{Estado de discernimento}

Vivemos num mundo pluralista. Este é um tempo de diálogo. É tempo sério de discernimento. Necessário será rever posições. Preciso será ter posições. Muitas famílias não têm convicções e posicionamentos claros a respeito de projetos de vida. É tempo de solidificar convicções a respeito do sentido da vida a dois, da sexualidade humana, do compromisso de pessoas no casamento. Quais os valores familiares que precisam ser respeitados? Entramos então num amplo tempo de discernimento comunitário. As opções dos outros, diferentes das nossas, precisam ser levadas em consideração. Num mundo realmente pluralista será necessário o acolhimento das diferenças, numa postura de que não Podemos ser donos absolutos da verdade. Pais e filhos, esposos entre si, instaurarão um tempo de diálogo desarmado. Sempre se levará em conta aquilo que pode e precisa ser mudado e aquilo que, se rejeitado, poria em jogo a própria realidade da família Nosso tempo nos convida a termos espírito critico, sobretudo, diante de projetos familiares propostas pelos meios de comunicação. É tempo de discernimento.

\section{Família e afetividade}

Afetividade não quer dizer melosidade. Nunca, como hoje, a família precisa tanto ser espaço de acolhimento afetivo. Vivendo num mundo de massa, mundo corrido, mundo desumano, mundo anónimo, a família será lugar de expressão de afeto, carinho, ternura, aceitação de uns pelos outros. Há discriminações de toda sorte. Há competições hediondas. No lar, os membros da família se sentem acolhidos. Podem ser eles mesmos. Podem fazer a experiência do dom de si e do acolhimento do dom dos outros. Trata-se de viver em família um constante clima de mútua hospitalidade. Nesse clima de afetividade são derrubados e destruidos medos e solidões.

\section{Fumília aberta}

Cada família terá as suas convicções. Acreditará em seu projeto. Lutará por ele. Desejará sua estabilidade e duração. Pensará nos seus. Mas pensará também nos outros. Sairá rumo a outras vidas e outras histórias. Crendo em sua força de comunidade vital e amorosa, levará a outros seu projeto. Não o impõe, mas faz proposta dele. A família é aberta e solidária. A família interessa-se pelo mundo e quer que seus membros sejam solidários a outras famílias e a outros homens. A família cria uma trama de solidariedade e de co-responsabilidade que vai além das paredes de seu domicilio.

\section{Família que vive valores velhos e novos}

Há os pais e os filhos, mas há também os avós e os netos. Em nossos tempos praticamente restringe-se a famDia aos pais e filhos. Parece importante acolher também o torrencial de experiências dos antigos. A convivência com os avós é fundamental. Parece também importante acolher o novo que é vivido pelas gerações dos netos. A família tira do baú de sua história coisas novas e velhas. 


\section{CONCLUSÃO}

Ao final destas reflexões queremos fazer um ato de fé na fantasia, fundamento da sociedade e espaço de crescimento do homem e da mulher. Parece urgente:

- preparar os jovens para a constituição de uma família através de uma educação para o amor, para a responsabilidade e para compromisso;

- necessário rever a maneira como jovens e menos jovens encaram a sexualidade que não pode ser desvinculada de um compromisso sério e alegre entre pessoas, do amor e da acolhida dos filhos;

- necessário levar os jovens esposos à prática do diálogo desde o tempo do namoro: nunca se construirá o casal e não se poderá solidificar a família quando os posicionamentos radicais não conhecem espaços de diálogo que não é apenas dizer coisas, mas acolher a diferença;

\section{BIBLIOGRAFIA}

IV Conferência Geral do CELAM de Santo Domingo, Texto oficial da CNBB, 219:12, Pctrópolis, Ed. Voas, 1992.
- denunciar toda sorte de injustiça social que impede à família de realizar sua missão: ser encontro amoroso entre um homem e uma mulher e espaço de acolhimento dos filhos;

- defender concepções mínimas de dignidade para a família: possibilidade de salários dignos, moradia, saúde, educação;

- desenvolver um trabalho sério e persistente junto aos memnos e meninas de rua, no sentido de que sejam reintegrados às famílias de origem ou famílias substitutas preparando-as para seu acolhimento;

- dar lugar aos idosos da família, no sentido de que sua experiência é fundamental para a construção de cada nova família que se funda;

- batalhar para que seja eliminada uma mentalidade abortista e antevida;

- crer que a família pode ser mola propulsora do surgimento de uma sociedade humana, solidária, justa e altruísta.

JOÃO PAULO II. Carta aos Chefes de Estado. L'Osservatore Romano, 17 (1272):1, abr, 1994.

recebido em: 19/0 7/94 aprovado em: 14/09/94 